\title{
Human Mars Ascent Vehicle Configuration and Performance Sensitivities
}

March 10, 2017, IEEE Aerospace Conference

Tara Polsgrove, Herbert D. Thomas, Walter Stephens, Tim Collins, Michelle Rucker, Mike Gernhardt, Matthew Zwack, Patrick Dees 


\section{Introduction}

- The MAV is the highest gear ratio element in human Mars mission architecture, growing by 5 to $9 \mathrm{~kg}$ for every $1 \mathrm{~kg}$ of added dry mass

- The MAV sets the cargo delivery requirement for the lander and the resulting lander mass, which in turn drives the Earth to Mars transportation system performance requirements.

- This paper explores MAV design sensitivities to

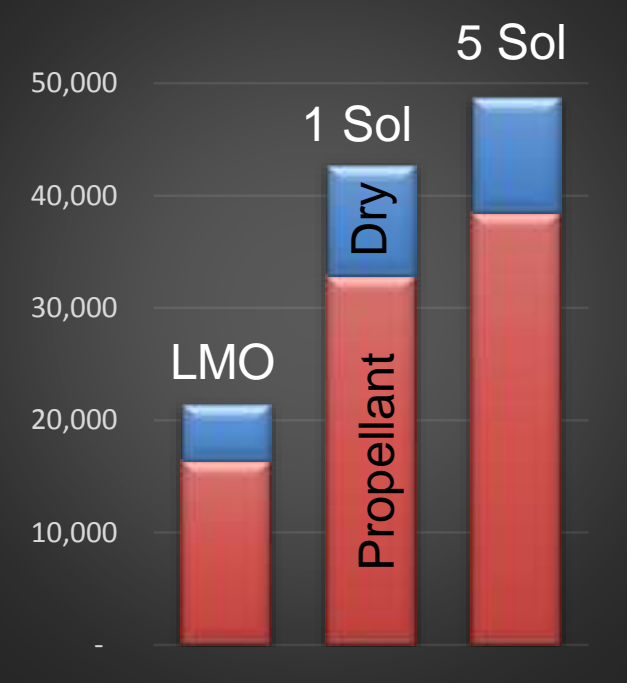
trajectory, propulsion, crew cabin size and the benefits and impacts of using a common crew cabin design.

- Related papers at this conference

- "Mars Ascent Vehicle Sizing, Habitability, and Commonality in NASA's Evolvable Mars Campaign" - Mike Gernhardt

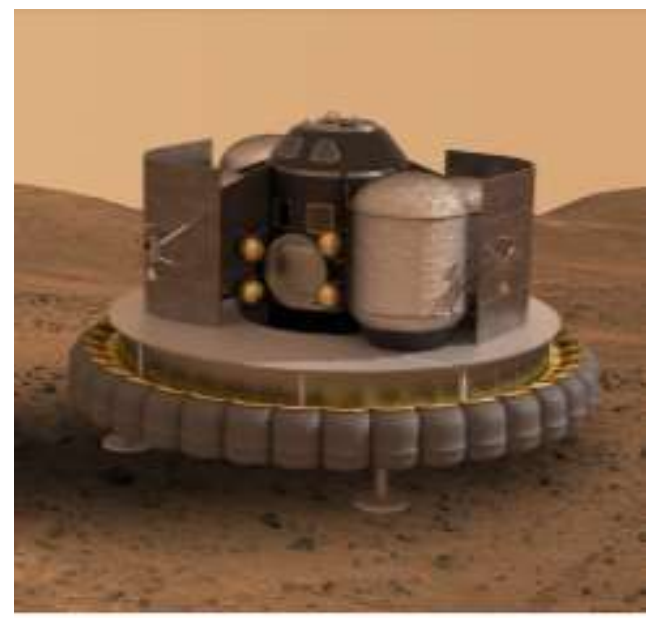




\section{Human Mars Ascent Vehicle}
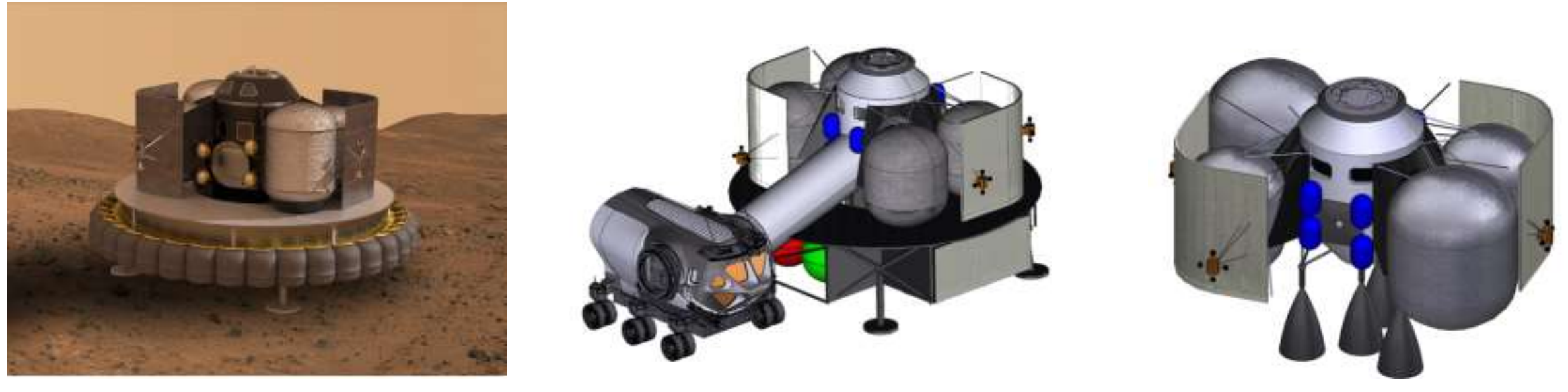

- The MAV is delivered to the Mars surface before crew arrive.

- It carries $4 \mathrm{crew}$ and $250 \mathrm{~kg}$ of science cargo off the surface.

- Crew ingress through pressurized tunnel so that surface suits can be left behind. This minimizes cabin volume requirements and limits contamination with Martian regolith.

- MAV configurations that minimize CG height and total height improve lander performance 


\section{Configuration Overview: Vertical Cabin}

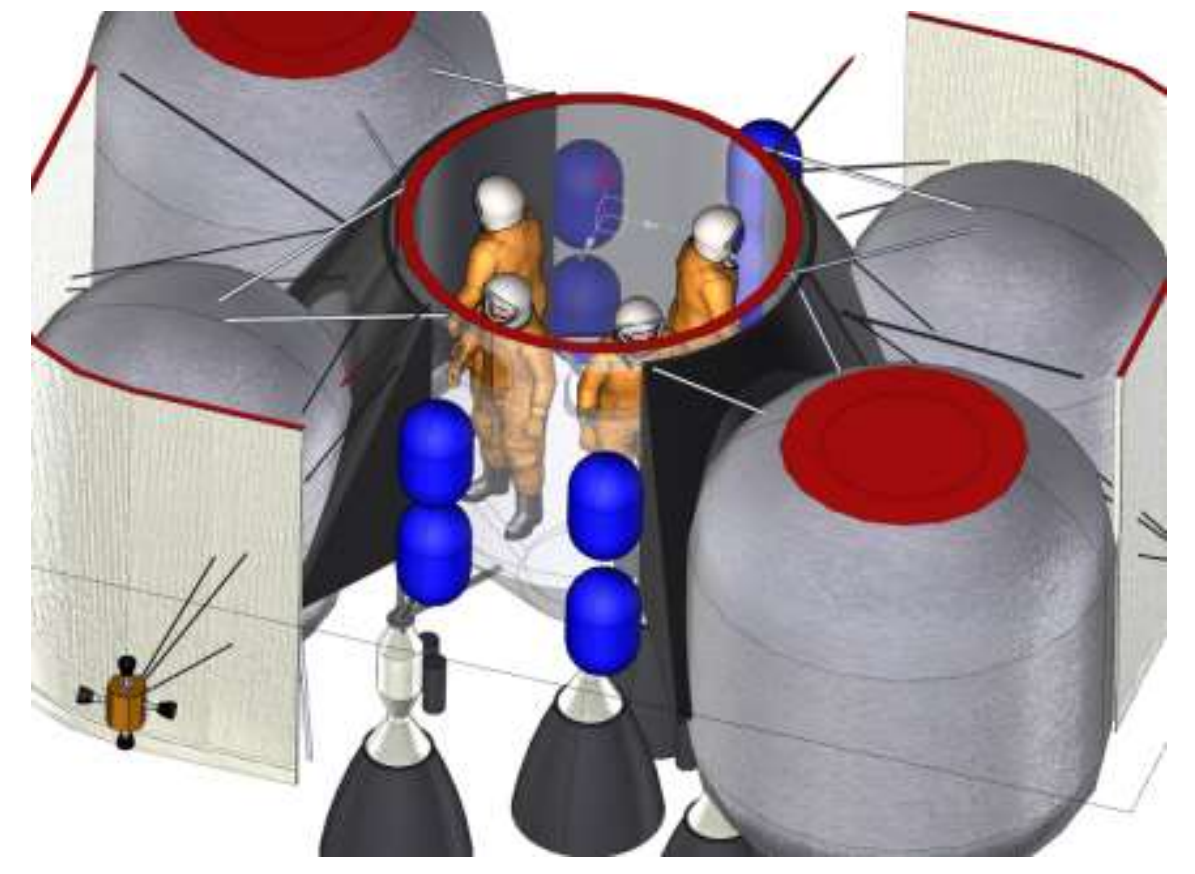

- Ascent acceleration of 0.8-1.5 Earth g's, could be a problem for a deconditioned crew, recumbent seating desired but drives cabin size

- A minimal cabin size with standing restraints was also assessed

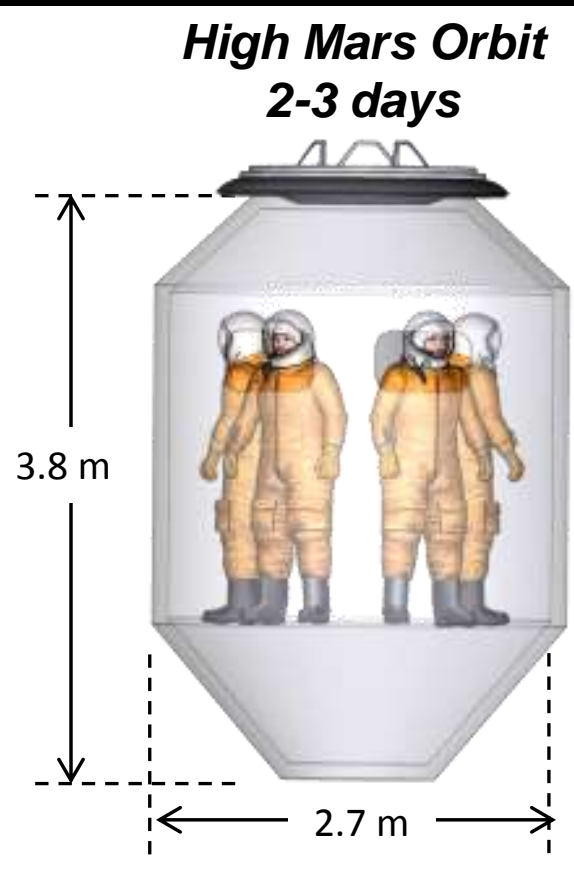

\section{Low Mars Orbit \\ 8-12 hours}
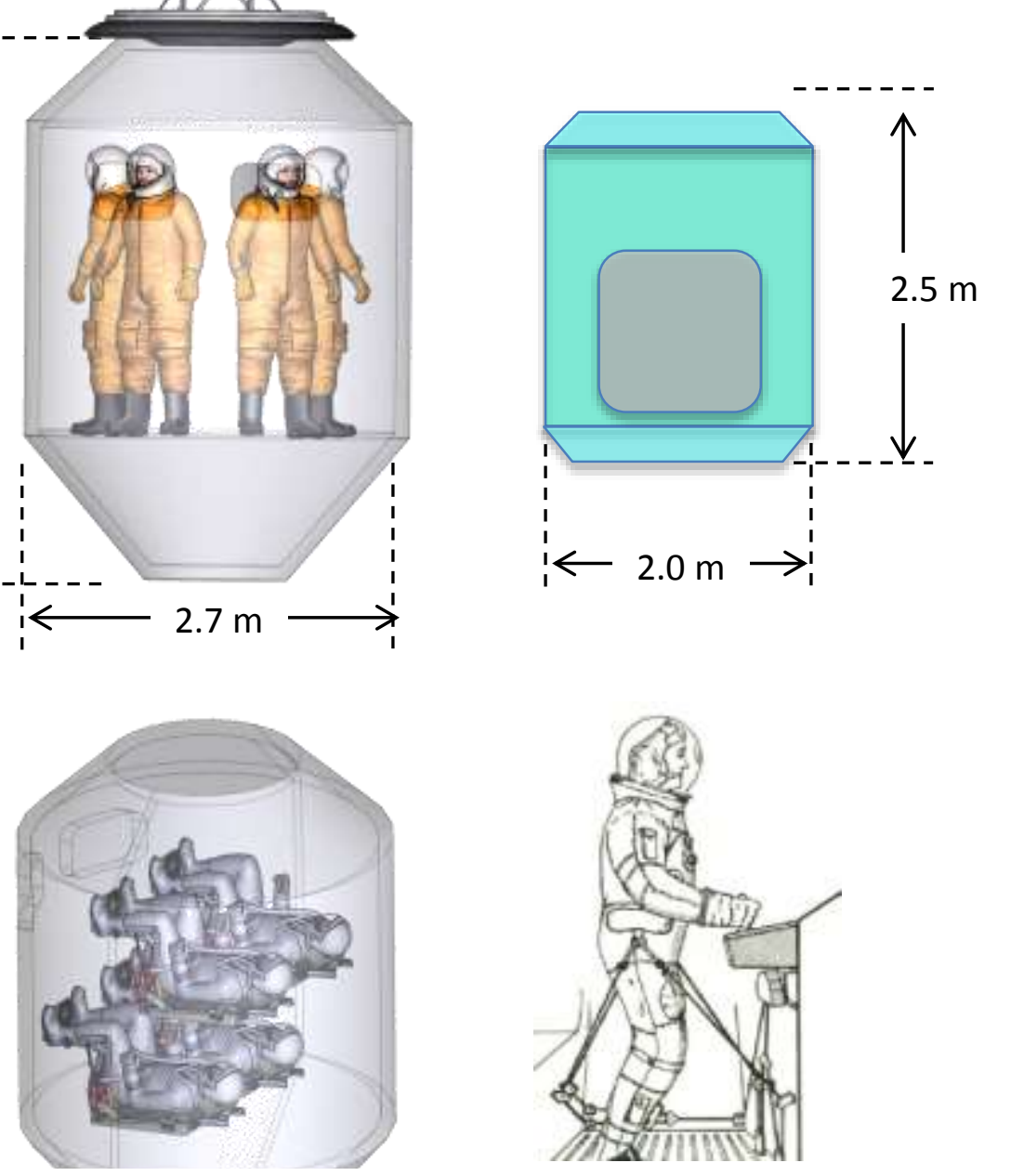

Recumbent seating

\section{.}




\section{Ascent Trajectory}

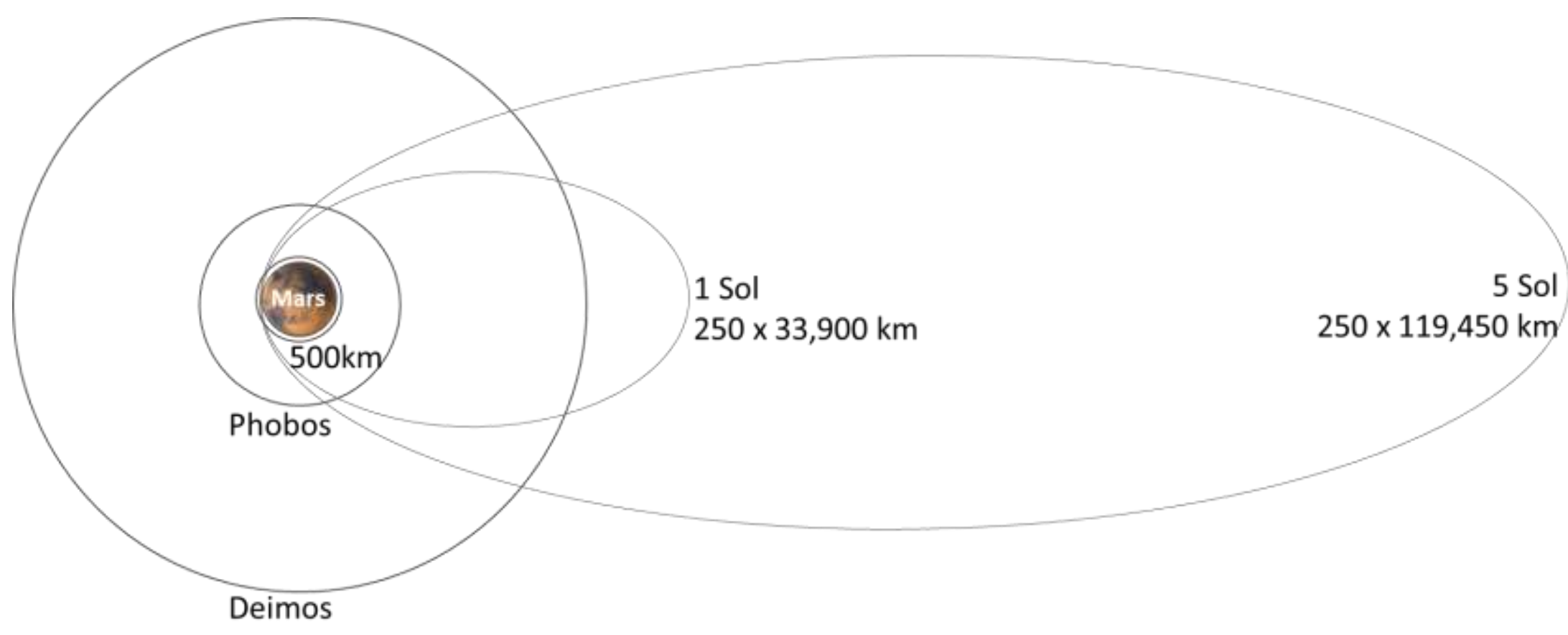

- Ascent to 3 target orbits is assessed, $500 \mathrm{~km}$ circ, 1 Sol, and 5 Sol

- Earth return vehicle will be in a high Mars orbit, 1 Sol - 5 Sol

- Ascent to low mars orbit minimizes MAV mass, but would require another vehicle to complete ascent and rendezvous with the Earth return vehicle. 


\section{Ascent Trajectory}

Rendezvous \&

Docking

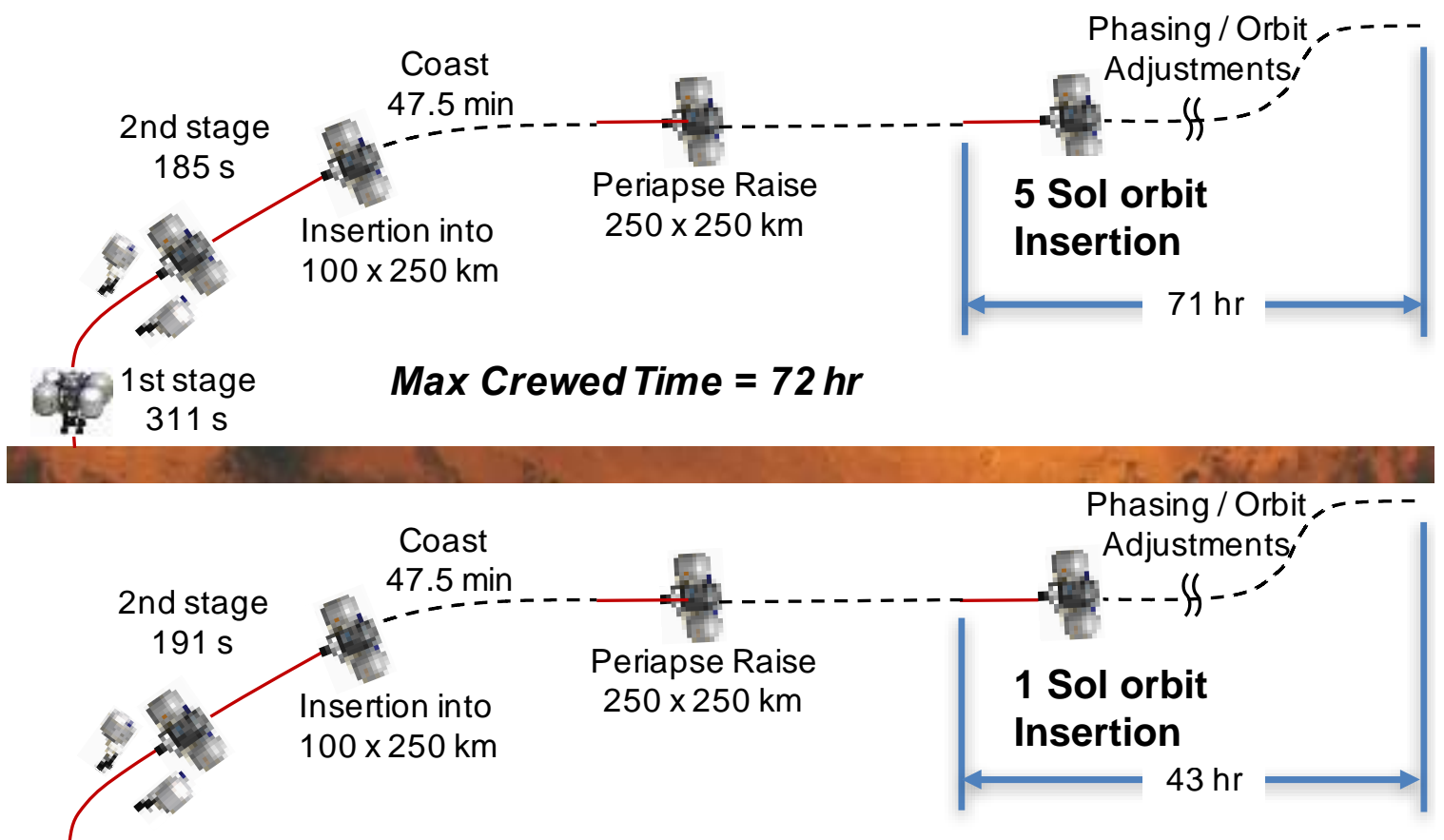

Max Crewed Time $=44 \mathrm{hr}$

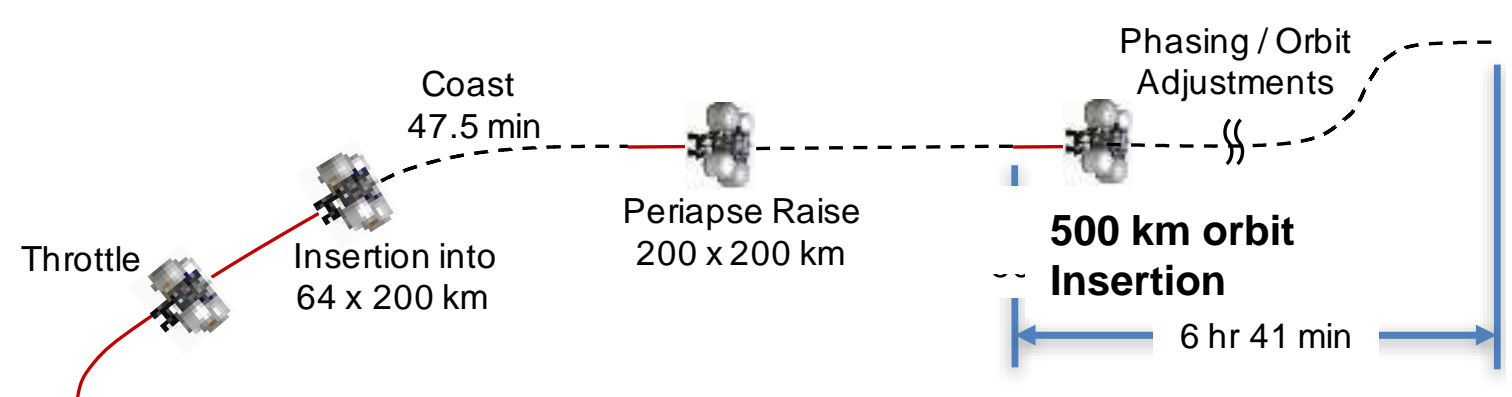

Max Crewed Time $=8 \mathrm{hr}$

\section{Configuration at Liftoff}

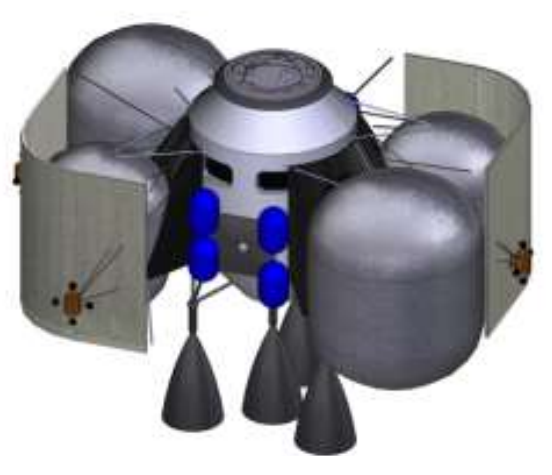

Configuration After Staging

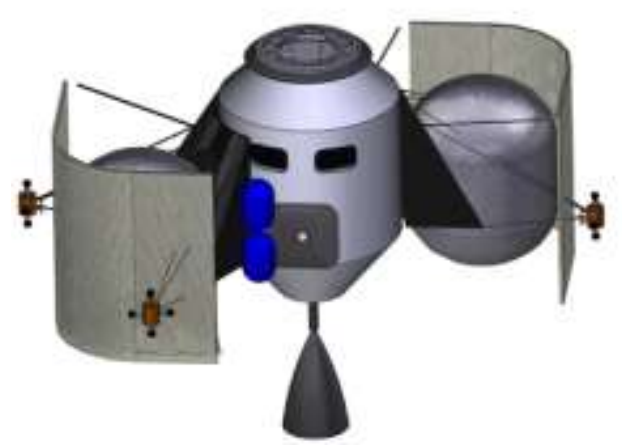




\section{Ascent Performance Sensitivities: 1 Sol}

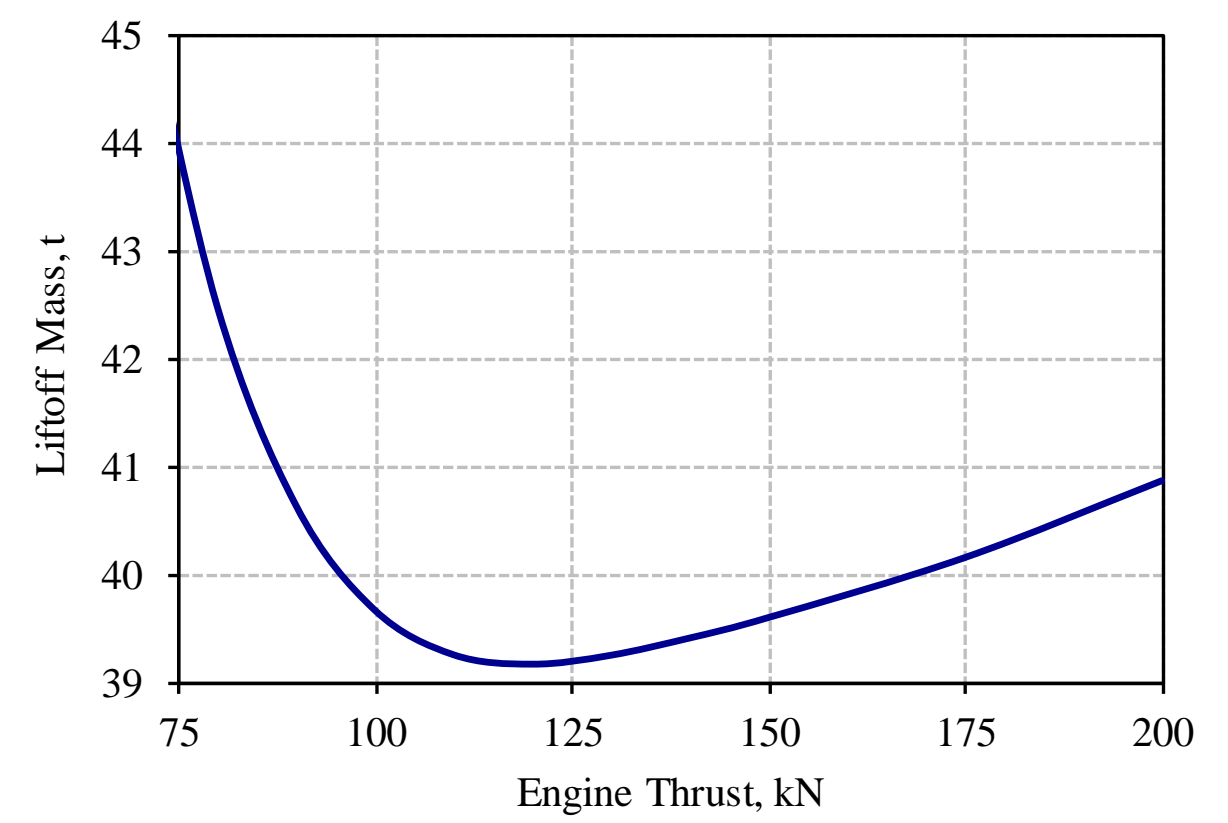

\section{Liftoff Mass vs Engine Thrust}

3 engine $1^{\text {st }}$ stage

1 engine $2^{\text {nd }}$ sage

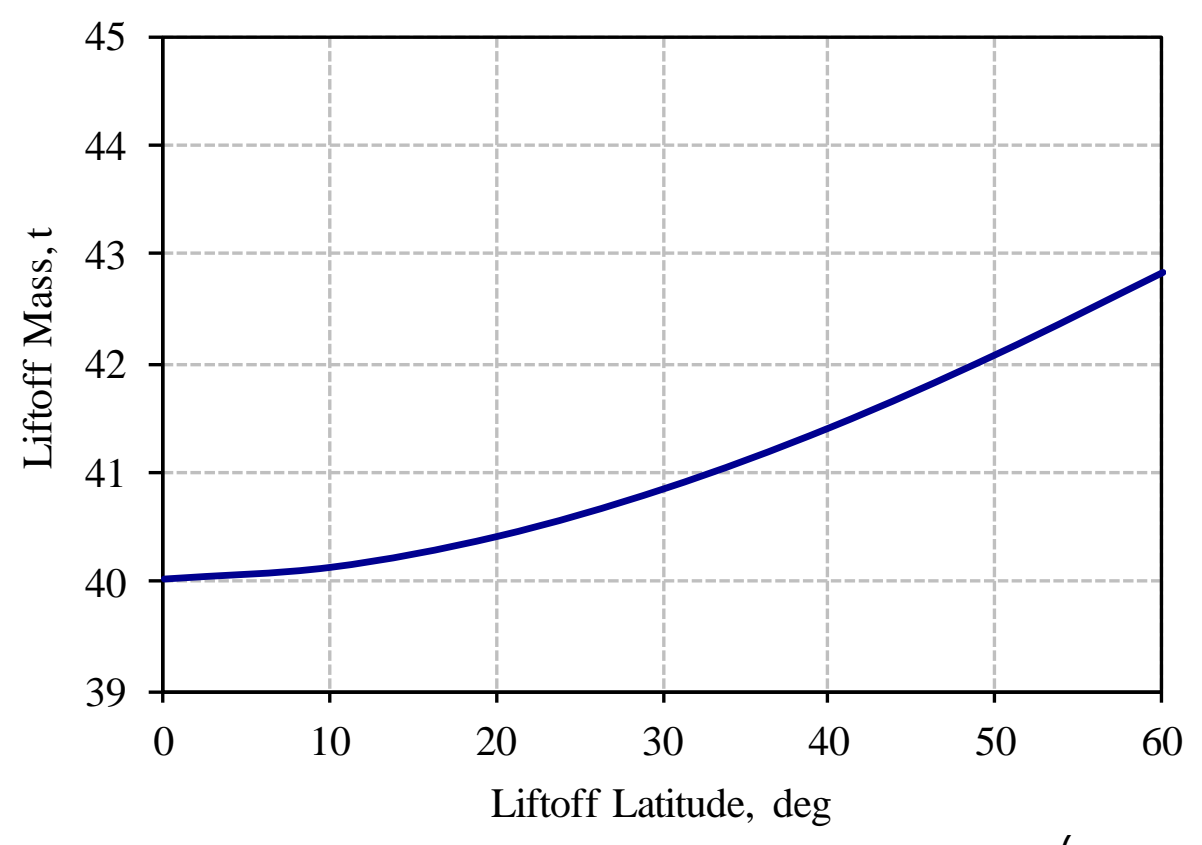

Liftoff Mass vs Latitude

Liftoff Latitude, deg 


\section{Ascent Performance Sensitivities: 5 Sol}

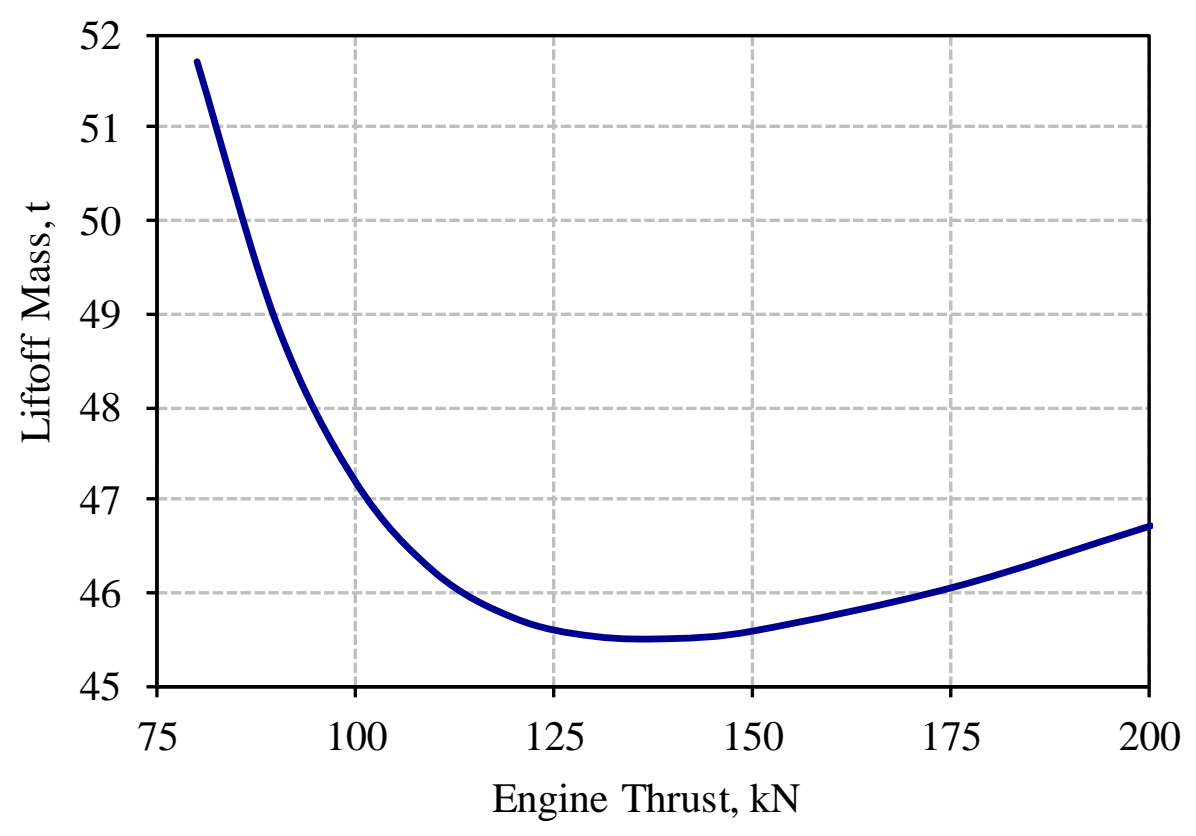

Liftoff Mass vs Engine Thrust 3 engine $1^{\text {st }}$ stage 1 engine $2^{\text {nd }}$ sage

Liftoff Mass vs Latitude

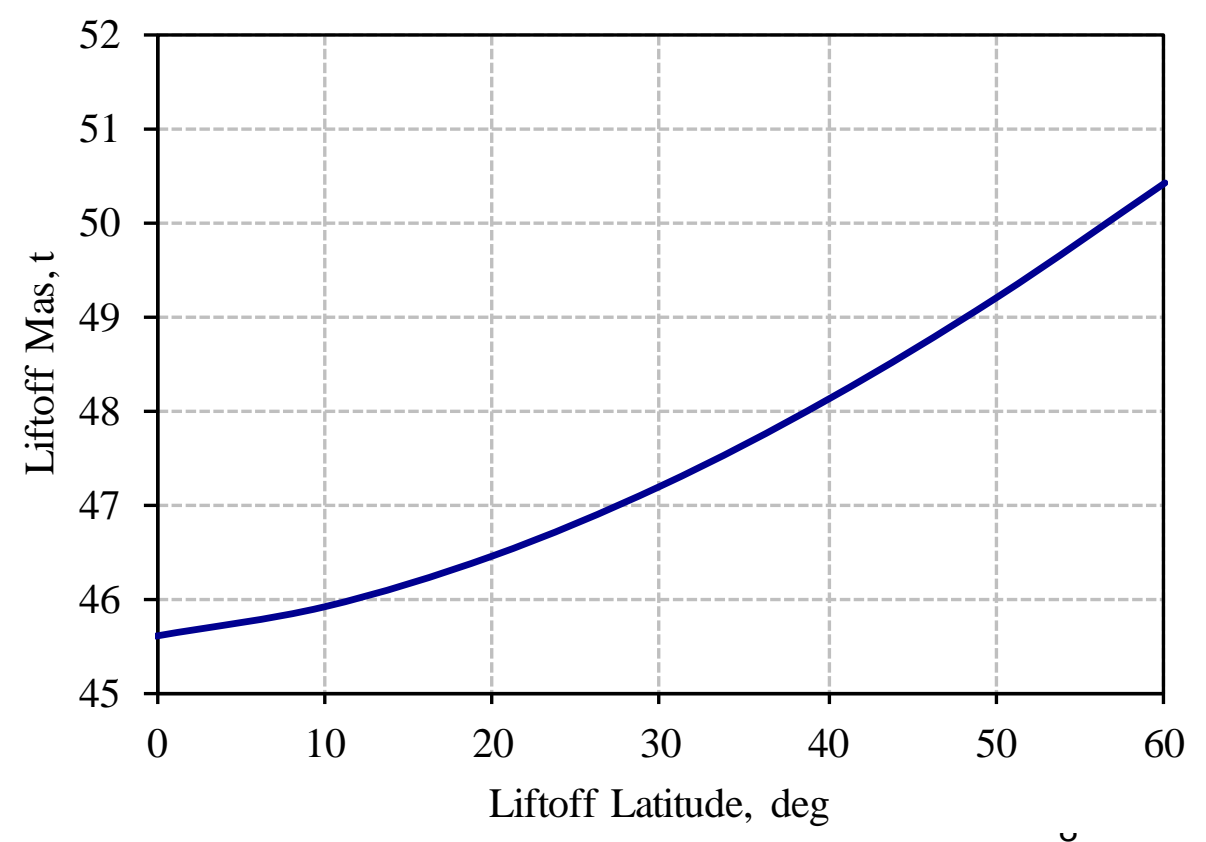




\section{Ascent Performance Sensitivities: 500 km}

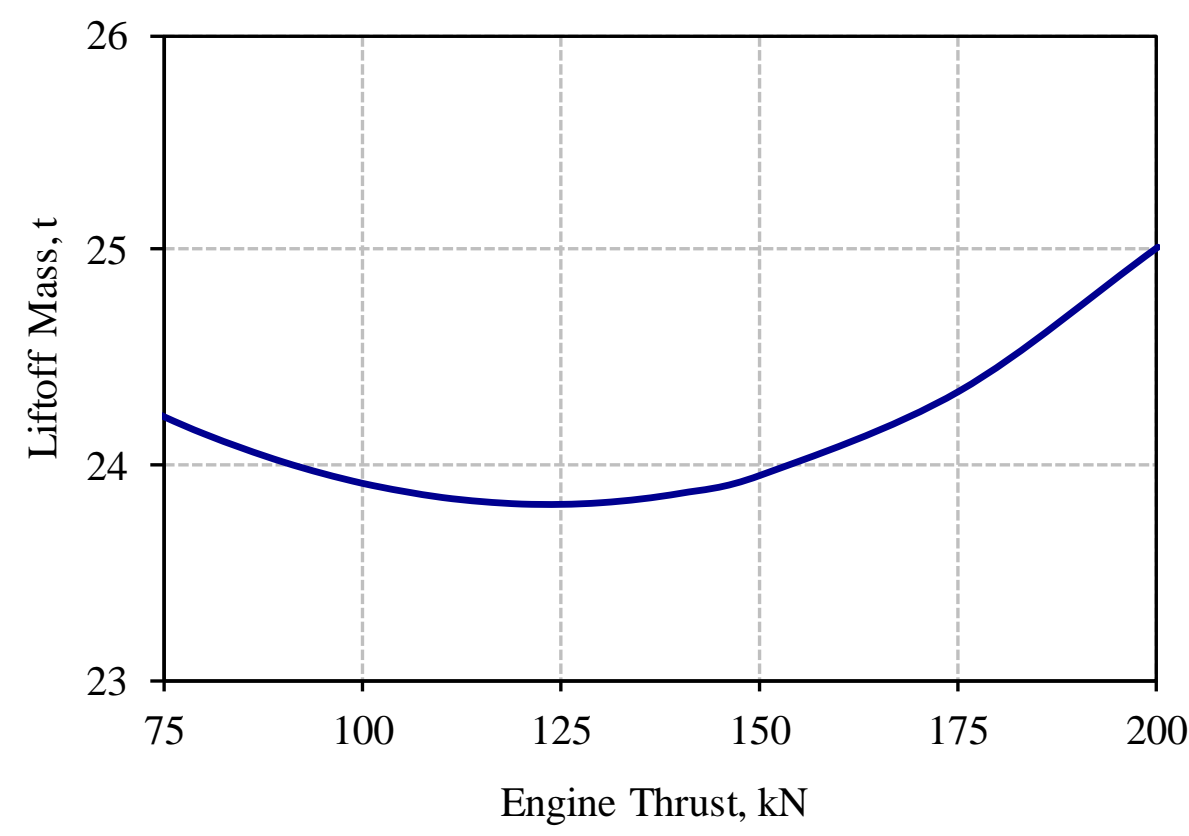

\section{Liftoff Mass vs Engine Thrust}

3 engine single stage

Liftoff Mass vs Latitude

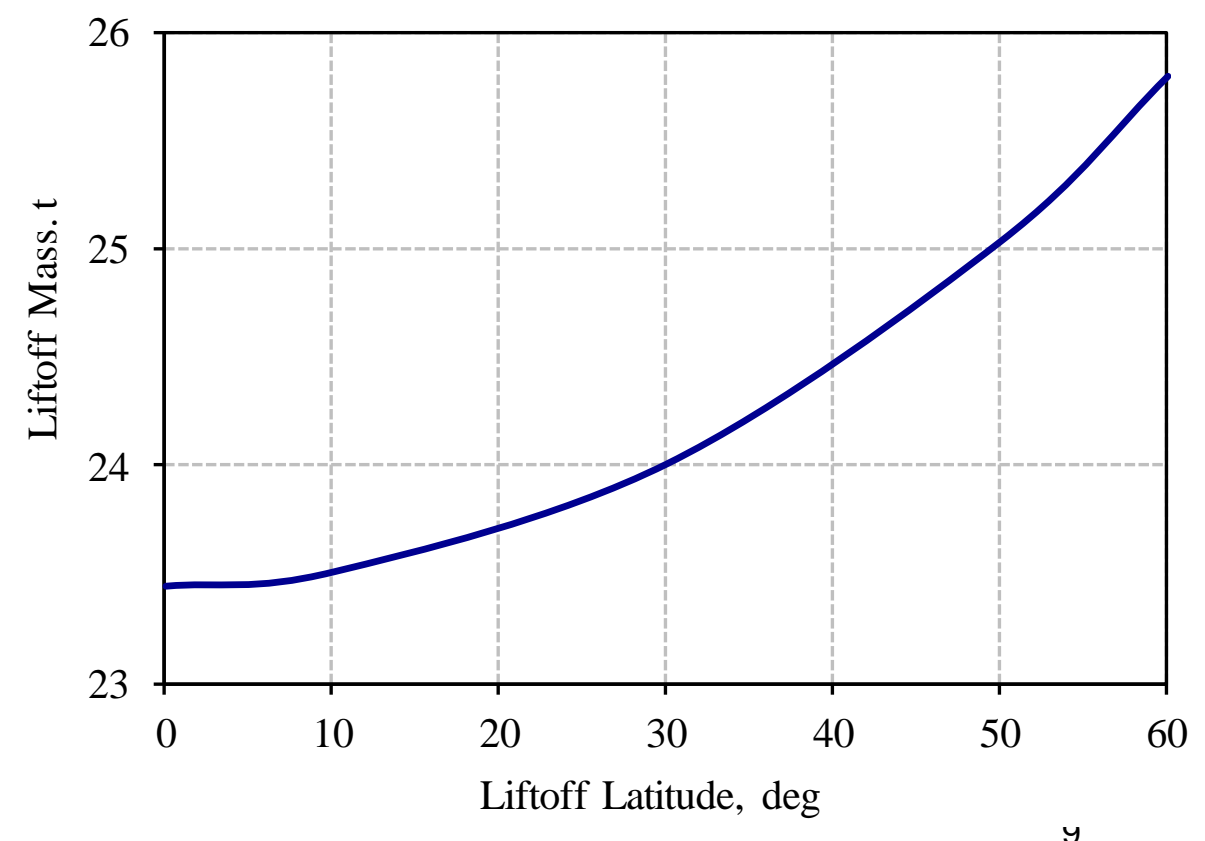




\section{MAV Performance Summary}

- Multidisciplinary team developed designs for 3 MAV options

- Protecting for +/- 30 deg latitude launch sites

\begin{tabular}{|l|c|c|c|}
\hline Target Orbit & 1 Sol & 5 Sol & $500 ~ \mathbf{~ m}$ \\
\hline Habitable Duration (hrs) & 44 & 72 & 8 \\
\hline Number of Crew & 4 & 4 & 4 \\
\hline Ascent Cargo (kg) & 250 & 250 & 250 \\
\hline MAV cabin mass (mt) & 4.2 & 4.3 & 3.9 \\
\hline Propellant & 25.0 & 29.2 & NTO: 12.2 \\
\hline \multicolumn{1}{|c|}{ Oxygen (mt) } & 7.9 & 9.2 & MMH: 6.2 \\
\hline \multicolumn{1}{|c|}{ Methane (mt) } & $300 / 100$ & $300 / 100$ & 300 \\
\hline Thrust (kN) & $20 \%$ & $20 \%$ & $20 \%$ \\
\hline Minimum Throttle & 42.9 & 48.9 & 24.4 \\
\hline Liftoff Mass (mt) & 17.2 & 19.0 & 23.7 \\
\hline MAV mass delivered to Mars Surface & & & \\
\hline assuming ISRU LOX production (mt) & & &
\end{tabular}




\section{Common Crew Cabin}
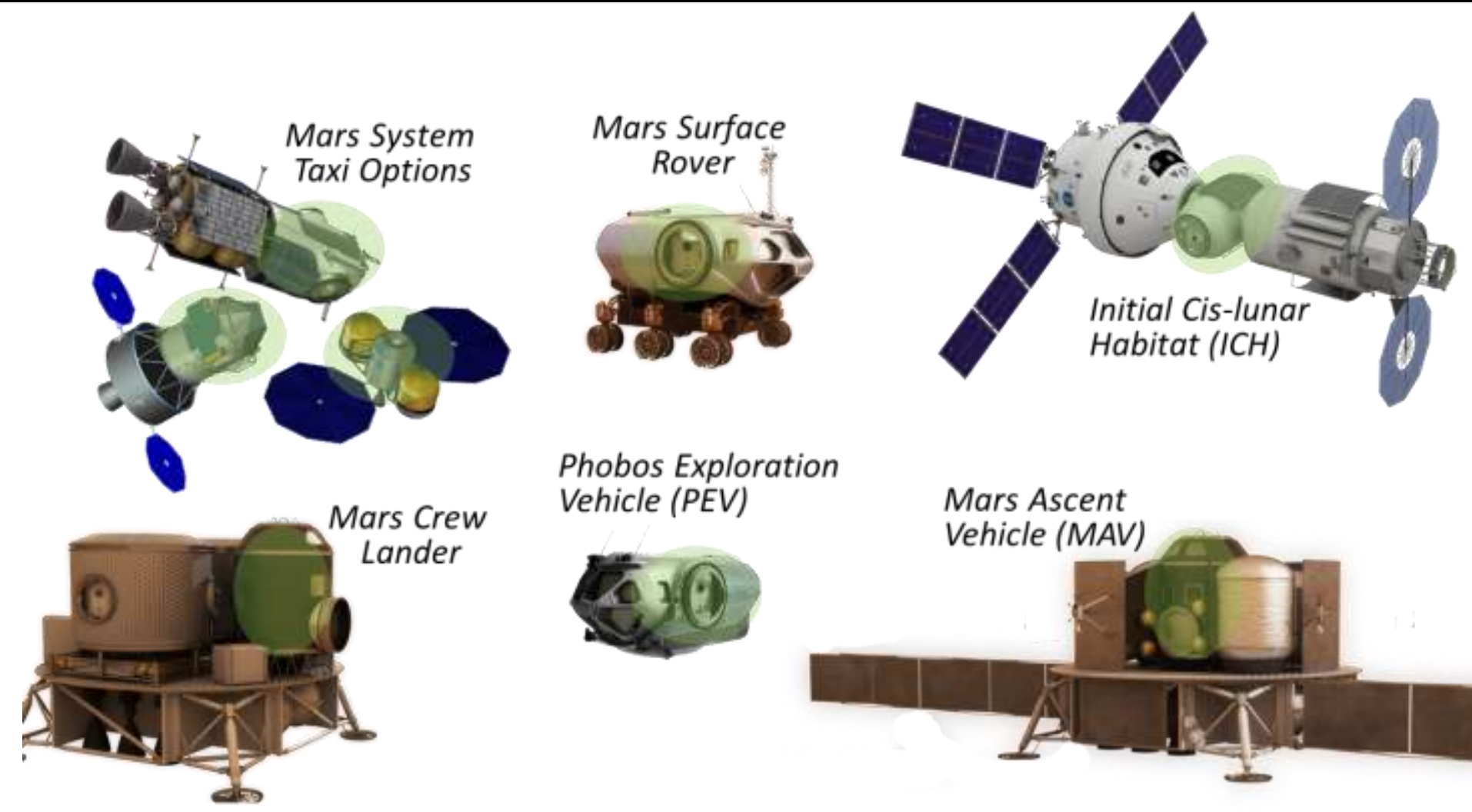

Phobos Exploration Vehicle (PEV)

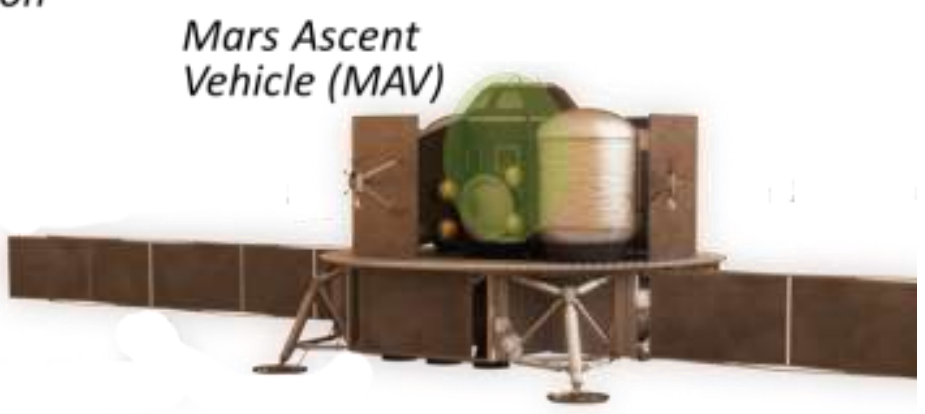

- There are many possible uses for a small crew cabin for cislunar and Mars missions

- A common crew cabin used in multiple applications may reduce overall development costs 


\section{Common Crew Cabin}
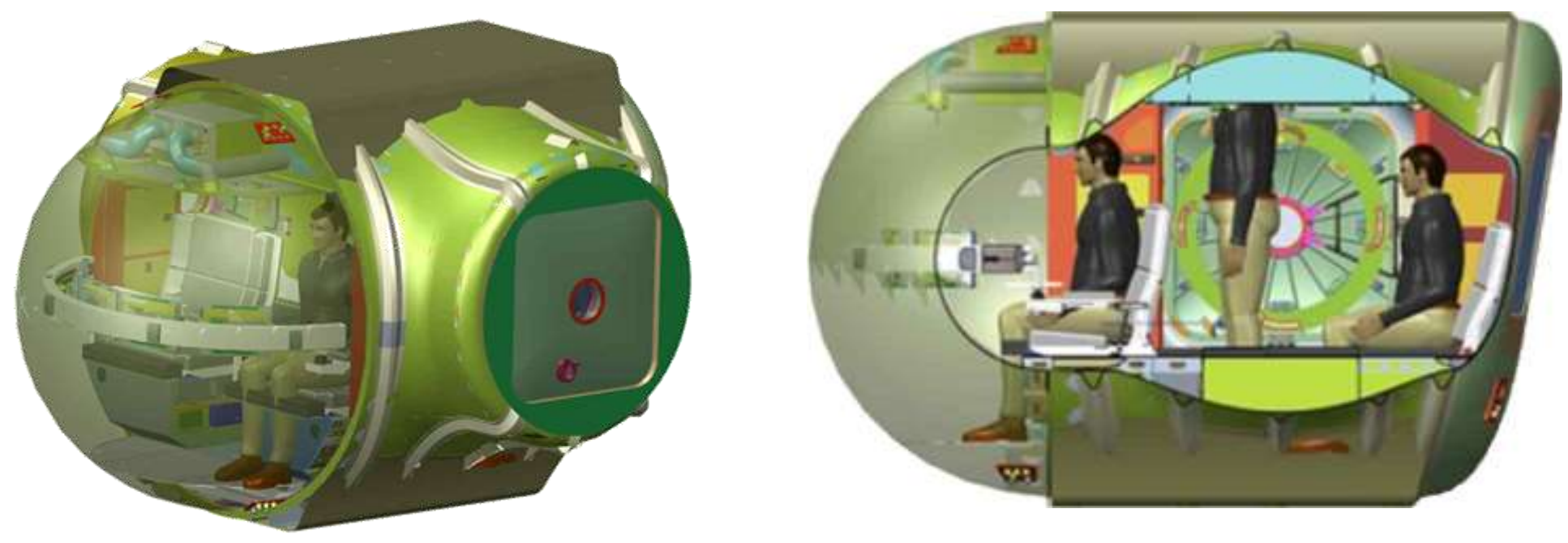

- A horizontal orientation was chosen for the common crew cabin study because it is better suited to the pressurized rover application and recent mock up evaluations show that it can function well as an ascent cabin. 


\section{Common Crew Cabin Configuration Trade Study}

- Several propellant tank packaging options were considered. Each constrained to fit within a $10 \mathrm{~m}$ diameter SLS fairing.

- 5 options were selected for further evaluation
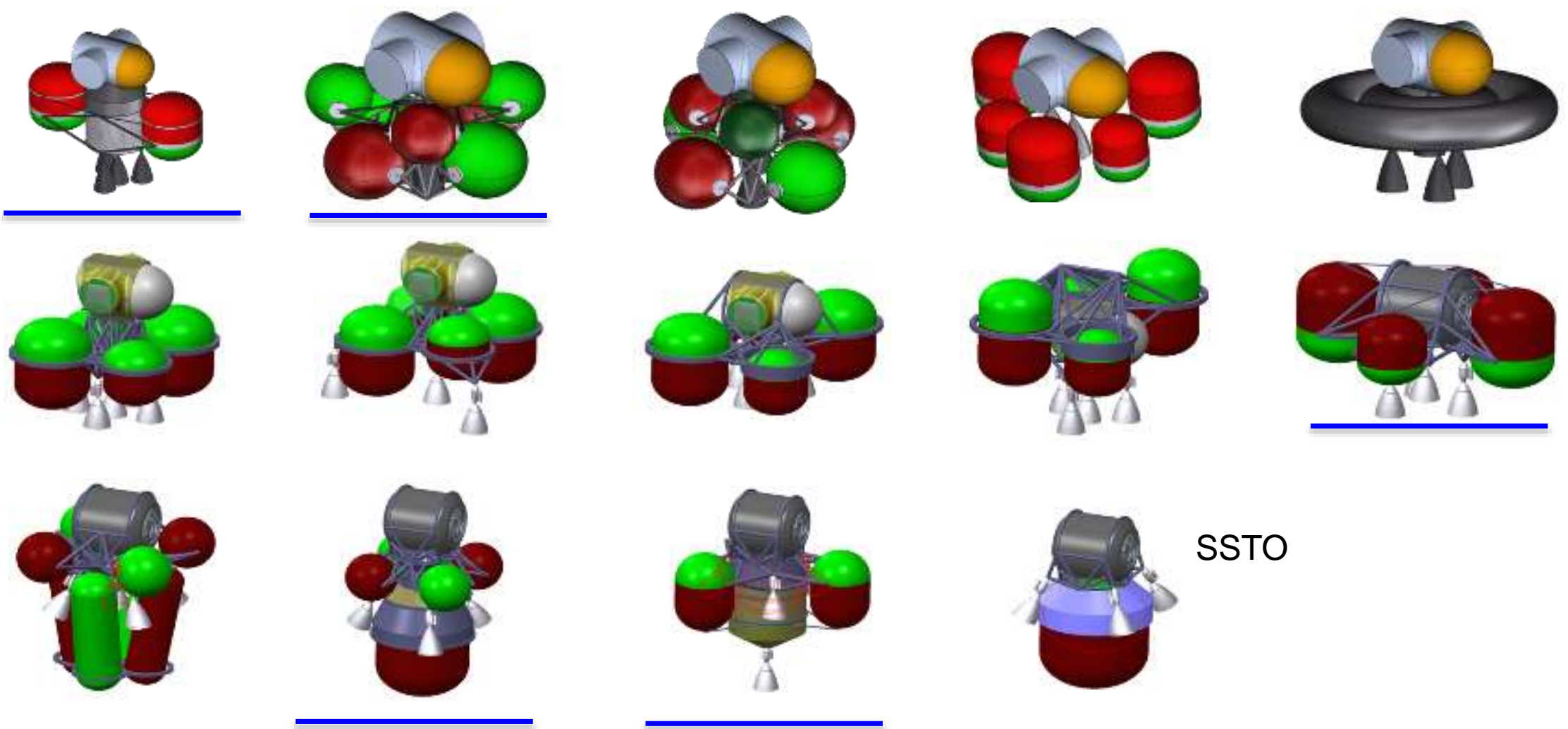


\section{Common Crew Cabin Configuration Trade Study}

- Concepts were ranked using the pair-wise comparison techniques of the Analytical Hierarchy Process (AHP) with equal weighting on all FOMs

\begin{tabular}{|l|c|}
\hline \multicolumn{1}{|c|}{ FOM } & Associated Considerations \\
\hline $\begin{array}{l}\text { 1-Structural } \\
\text { System }\end{array}$ & $\begin{array}{c}\text { mass, load path, simplicity, HMAV } \\
\text { support structure }\end{array}$ \\
\hline $\begin{array}{l}\text { 2-Propulsion } \\
\text { System }\end{array}$ & $\begin{array}{c}\text { mass, tank geometry and complexity, } \\
\text { number of tanks }\end{array}$ \\
\hline $\begin{array}{l}\text { 3-Center of } \\
\text { Gravity }\end{array}$ & $\begin{array}{c}\text { c.g. height at launch and during entry, } \\
\text { descent, and landing }\end{array}$ \\
\hline $\begin{array}{l}\text { 4-Deck } \\
\text { Space }\end{array}$ & $\begin{array}{c}\text { space for non MAV cargo, radiators, solar } \\
\text { arrays, other subsystems }\end{array}$ \\
\hline 5-Access & $\begin{array}{c}\text { crew access, accommodation of } \\
\text { ingress/egress tunnel }\end{array}$ \\
\hline $\begin{array}{l}\text { 6-Design } \\
\text { Flexibility }\end{array}$ & $\begin{array}{c}\text { sensitivity to future changes in } \\
\text { requirements, ability to evolve }\end{array}$ \\
\hline
\end{tabular}

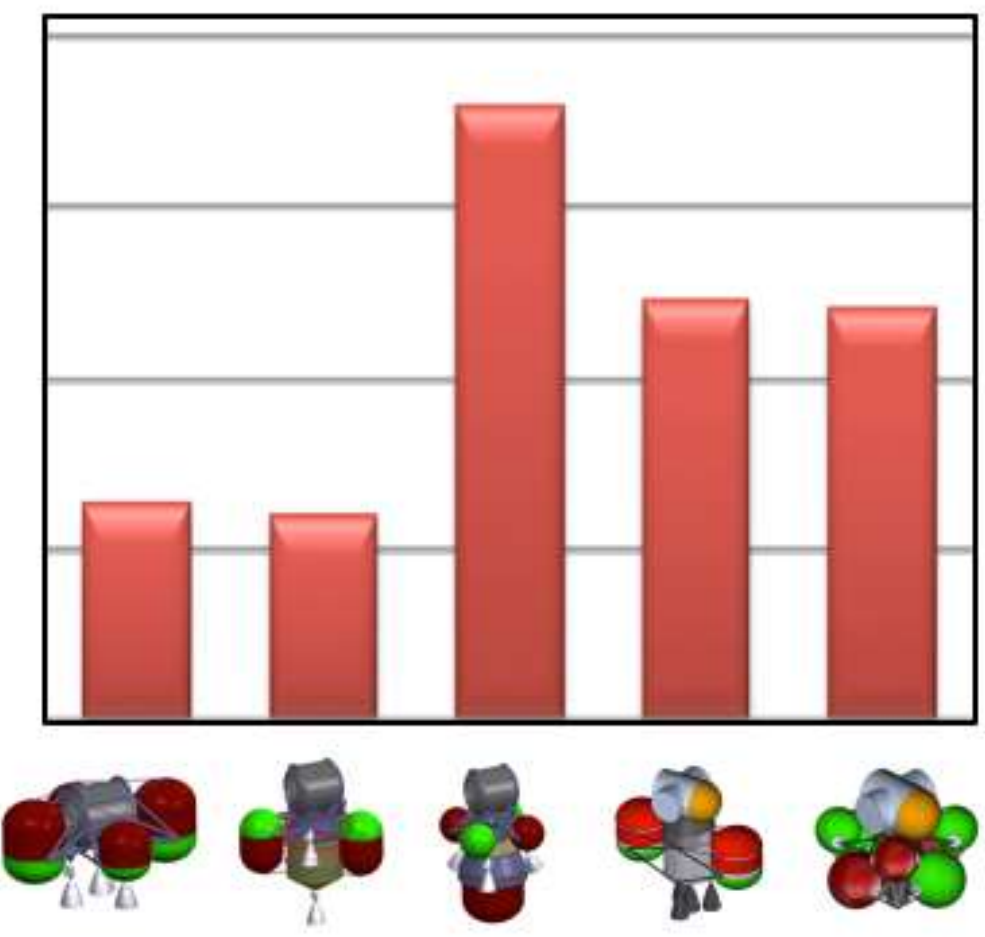




\section{Common Crew Cabin}

- To fairly evaluate the effects of using a common rover-derived cabin for the MAV, several cabin geometries were assessed with the same propulsion system configuration

\section{Al (Metal) Cabin}

Non Optimal Shape

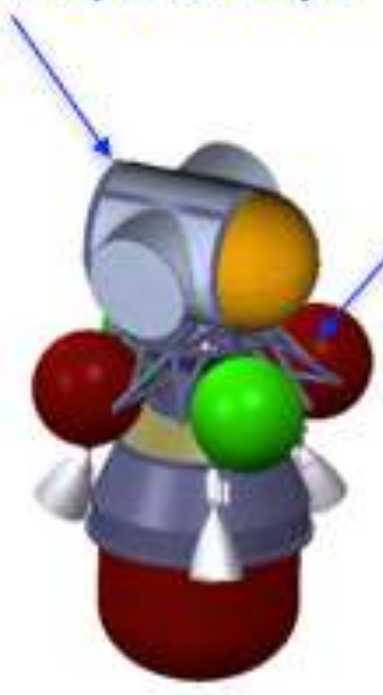

Common Cabin
Extra Support for Horizontal

Configuration (notional here)

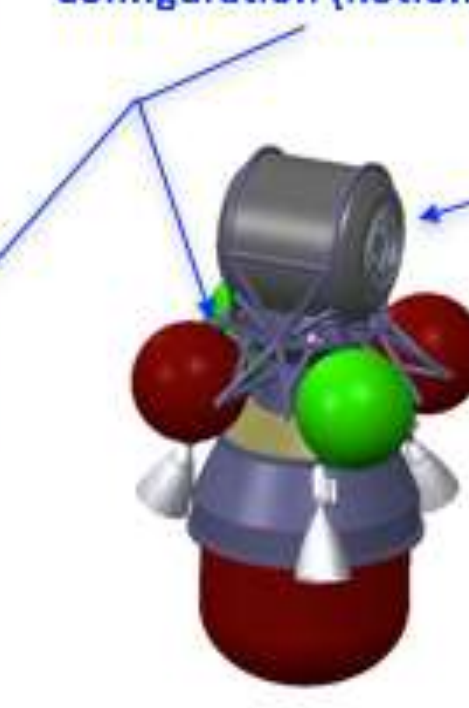

Horizontal Cylindrical Cabin

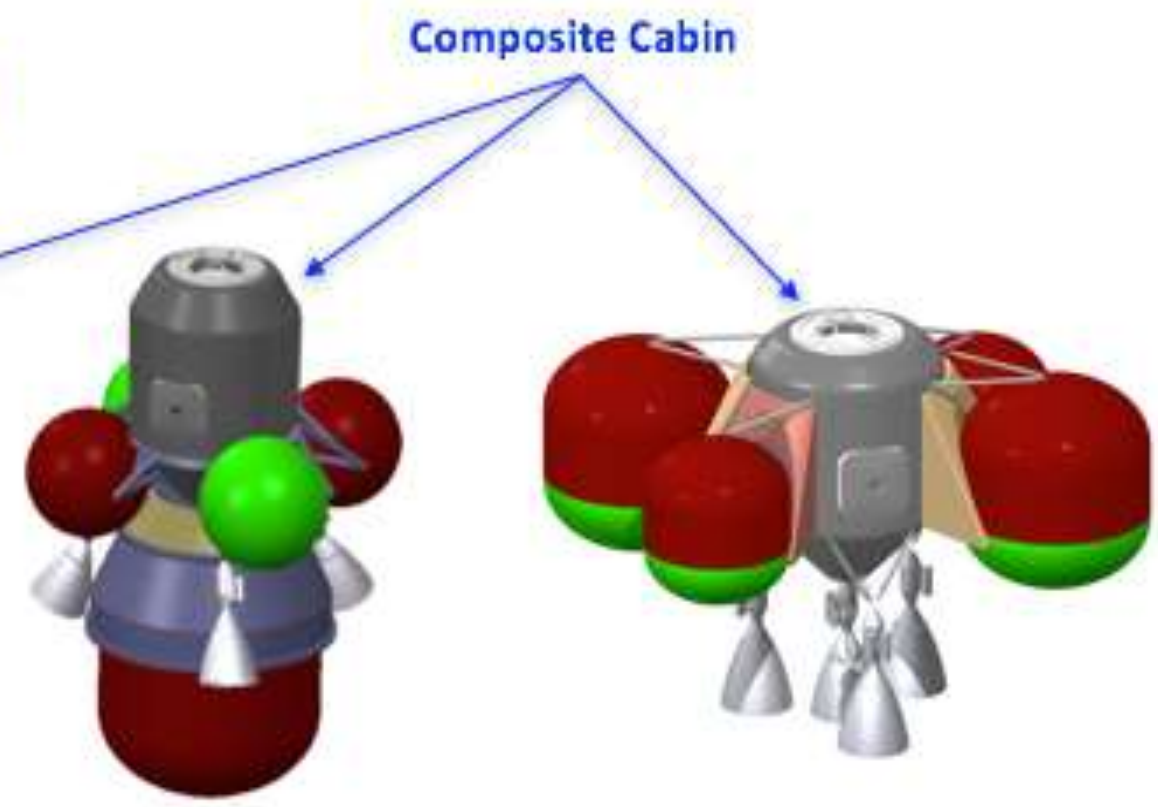

Vertical Cylindrical Cabin
POD MAV

(previous design) 


\section{Common Crew Cabin Lander Integration}

- The leading MAV configuration with the common crew cabin is taller than the previous vertical cabin design.

- Crew must ascend a greater distance to ingress the vehicle.

- It appears the taller configuration allows for greater packaging volume for additional equipment around the MAV
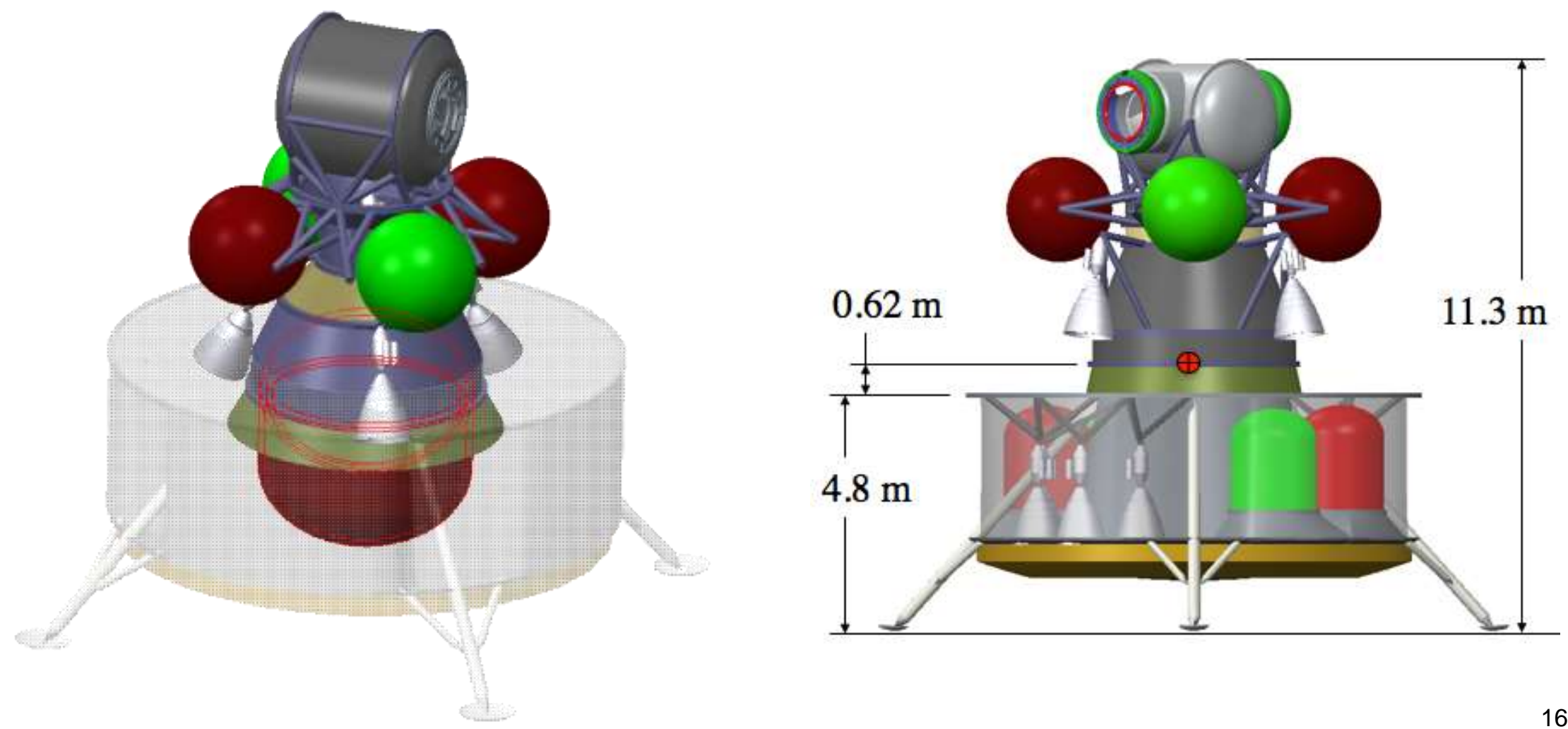


\section{Common Crew Cabin Structural Analysis}

\begin{tabular}{|c|c|c|c|c|}
\hline Structure & $\begin{array}{l}\text { Common Cabin } \\
\text { (Horizontal) }\end{array}$ & $\begin{array}{l}\text { Cylindrical Cabin } \\
\text { (Horizontal) }\end{array}$ & $\begin{array}{l}\text { Cylindrical Cabin } \\
\text { (Vertical) }\end{array}$ & $\begin{array}{c}\text { Previous POD } \\
\text { MAV }\end{array}$ \\
\hline Cabin & 896 & \multirow{3}{*}{$\begin{array}{l}\text { Results foll between the } \\
\text { Common Cabin and } \\
\text { Verical Cabin Coses } \\
\text { (not analyzed) }\end{array}$} & 648 & 760 \\
\hline $1^{\text {st }}$ Stage & 304 & & 366 & 232 \\
\hline $2^{\text {nd }}$ Stage & 313 & & 251 & 127 \\
\hline Total (Primary) & 1,513 & $\sim 1,390$ (estimate) & 1,265 & 1,119 \\
\hline MAV Adapter & 85 & 85 & 85 & 174 \\
\hline
\end{tabular}

- Comparison of MAV primary structure shows vertical crew cabin MAV to be more structurally efficient by $200-300 \mathrm{~kg}$. Additional refinements of the common cabin structural design may reduce this difference.

- While it appears that the common cabin will result in higher MAV vehicle mass, the benefit of a common cabin development across the entire architecture may outweigh the cost in MAV performance. 


\section{Conclusions}

- Mars ascent vehicle mass varies significantly with the target orbit, propulsion, and cabin design choices.

- Decisions about MAV design and performance must be considered in the context of the end to end mission architecture

- Choices that minimize MAV mass may result in additional mission complexity

- Choices that result in a heavier MAV may minimize development cost across the architecture. 


\section{Questions?}

